\title{
Multiyear Variability in the Tasman Sea and Impacts on Southern Hemisphere Climate in CMIP5 Models ${ }^{\mathscr{O}}$
}

\author{
Christine T. Y. Chung And Scott B. Power \\ Bureau of Meteorology, Melbourne, Victoria, Australia \\ Agus SANTOSO \\ Australian Research Council Centre of Excellence for Climate System Science, University of \\ New South Wales, Sydney, New South Wales, Australia \\ GUOMIN WANG \\ Bureau of Meteorology, Melbourne, Victoria, Australia
}

(Manuscript received 1 December 2016, in final form 23 February 2017)

\begin{abstract}
Naturally occurring multiyear to decadal variability is evident in rainfall, temperature, severe weather, and flood frequency around the globe. It is therefore important to understand the cause of this variability and the extent to which it can be predicted. Here internally generated decadal climate variability and its predictability potential in an ensemble of CMIP5 models are assessed. Global hot spots of subsurface ocean decadal variability are identified, revealing variability in the southern Tasman Sea that is coherent with variability in much of the Pacific Ocean and Southern Hemisphere. It is found that subsurface temperature variability in the southern Tasman Sea primarily arises in response to preceding changes in Southern Hemisphere winds. This variability is multiyear to decadal in character and is coherent with surface temperature in parts of the Southern Hemisphere up to several years later. This provides some degree of potential predictability to surface temperature in the southern Tasman Sea and surrounding regions. A few models exhibit significant correlation between subsurface variability in the southern Tasman Sea and zonally averaged precipitation south of $50^{\circ} \mathrm{S}$; however, the multimodel mean does not exhibit any significant correlation between subsurface variability and precipitation. Models that exhibit stronger subsurface variability in the southern Tasman Sea also have a stronger interdecadal Pacific oscillation signal in the Pacific.
\end{abstract}

\section{Introduction}

Multiyear to decadal variability is evident in rainfall, temperature, severe weather, and flood frequency around the globe, including the Southern Hemisphere (Power et al. 2017, manuscript submitted to CLIVAR Exchanges). This can cause hardship and loss of life (see, e.g., Power et al. 2005; Power and Callaghan 2016). It is therefore important that we understand the cause of this variability and the extent to which it can be predicted. While the warming

Supplemental information related to this paper is available at the Journals Online website: http://dx.doi.org/10.1175/ JCLI-D-16-0862.s1.

Corresponding author e-mail: Christine T. Y. Chung, christine. chung@bom.gov.au trend in the oceans due to anthropogenic forcing in the late twentieth century has been extensively studied (e.g., IPCC 2013; Rhein et al. 2013, and references therein), the study of naturally occurring multiyear to multidecadal climate variability is hampered by the relatively short and sparse subsurface oceanic observations. This is particularly true in the South Pacific and other parts of the Southern Hemisphere (Power et al. 2017, manuscript submitted to CLIVAR Exchanges). To better understand the processes driving variability in oceans, and the extent to which this variability might be predictable, long-term simulations from climate models can be utilized (e.g., Kirtman et al. 2013). The multimodel mean and range of modeled teleconnections can potentially improve our understanding of the character, cause, and predictability of multiyear variability. Although climate models are imperfect (e.g., Flato et al. 2013), they have the potential 
to provide useful insights for instigating further research (Power et al. 2017, manuscript submitted to CLIVAR Exchanges).

In the ensemble from phase 5 of the Coupled Model Intercomparison Project (CMIP5), the time scale of variability in sea surface temperature (SST) and sea level height has been found to be latitudinally dependent (Monselesan et al. 2015). In the tropics, variability is dominated by El Niño-Southern Oscillation (ENSO) and occurs on approximately 5 -yr time scales, whereas at higher latitudes a greater fraction of the variability occurs on decadal time scales (Power and Colman 2006; Monselesan et al. 2015). Potential predictability studies have shown that in CMIP3 and CMIP5 ensembles, the fraction of predictable, internally generated decadal variability, for temperature and precipitation, is greatest in mid-to-high latitudes (Boer and Lambert 2008; Boer 2011; Boer et al. 2013, Kirtman et al. 2013). However, the reasons for this predictability potential are still far from being fully understood. Since the ocean interior contains stronger decadal variability than the surface (e.g., Chikamoto et al. 2013; Monselesan et al. 2015; Sloyan and O'Kane 2015), it is worth considering the extent to which the ocean subsurface is involved in this potential predictability.

Here we assess subsurface ocean variability and predictability in an ensemble of CMIP5 models. One region known to have strong decadal variability and potential multiyear predictability is the southern Tasman Sea (SthTas; Hill et al. 2008, 2011; Holbrook et al. 2011; Sloyan and O'Kane 2015). After a global assessment of subsurface ocean variability, we focus primarily on SthTas variability. We address two key questions of interest: 1) What influences decadal variability in the SthTas in the CMIP5 models? 2) To what extent can subsurface temperatures in the SthTas provide predictability for surface temperatures or rainfall elsewhere?

The SthTas overlaps the southern extension of the East Australia Current (EAC; Godfrey et al. 1980; Tilburg et al. 2001). It has been shown that large-scale, low-frequency variability in the SST and upper-level thermocline can be a reddened response to short time scale atmospheric forcing such as white noise in the surface heat flux and wind stress curl (Frankignoul and Hasselmann 1977). Previous observation-based studies have found that changes in the wind stress curl over the South Pacific correlate strongly with changes in the strength of the EAC extension and sea surface temperatures off the southeast coast of Tasmania on interannual and decadal time scales (Hill et al. 2008, 2011). Additionally, Sloyan and O'Kane (2015) found, using model reanalyses, that decadal variability in the Tasman Sea is driven by nonlinear responses to basinwide wind stress curl changes over the South Pacific. Several model-based studies have also reinforced the importance of Southern Hemispheric westerly winds on the oceans (e.g., Cai et al. 2003; Oke and England 2004; Hirabara et al. 2007). Oke and England (2004), for instance, found that a simulated periodic $5^{\circ}$ latitudinal shift of westerly winds over the Southern Ocean drove temperature variations of up to $0.4^{\circ} \mathrm{C}$ at depths of up to $900 \mathrm{~m}$.

There is also evidence that the interdecadal Pacific oscillation (IPO; Power et al. 1999) modulates the effect that ENSO has on variability in the Tasman Sea, with ENSO having a larger effect on the mean wave direction, and hence sea surface temperatures, during negative (La Niña like) IPO phases (Holbrook et al. 2011). Additionally, during negative IPO phases, subtropical winds are enhanced, driving an increase in warm sea surface temperature anomalies along the east coast of Australia (Goodwin et al. 2006; Holbrook et al. 2011). Given this earlier research, we will examine the role of the tropical Pacific in driving multiyear and decadal variability in the SthTas.

In section 2, we first identify oceanic "hot spots" where $40 \%$ or more of the $300-\mathrm{m}$ ocean temperature variability occurs on a decadal time scale. The rest of the study focuses on the SthTas. In section 3, we examine the link between subsurface temperature variability in the SthTas and both surface temperature and precipitation over the Southern Hemisphere. In section 4 we examine the physical mechanisms driving SthTas variability in the models through utilization of intermodel diversity. The results are summarized in section 5 .

\section{Decadal subsurface variability in CMIP5 models}

In this study we analyze the multimodel mean (MMM) of 22 CMIP5 models from the preindustrial control (PiC) simulations (Taylor et al. 2009, 2012). The PiC runs have prescribed atmospheric concentrations of $\mathrm{CO}_{2}$ (time-varying) and aerosols (constant) at preindustrial conditions, and are designed to simulate the internally generated, naturally occurring variability only. For the PiC runs, we use $500 \mathrm{yr}$ of output from each model. All model output is interpolated to a regular $1.5^{\circ} \times 1.5^{\circ}$ grid.

Annual means are computed from July to June the following year so that ENSO events, which tend to peak during austral summer, are fully contained within each year. Data from the PiC runs are linearly detrended over the entire 500-yr period to reduce the effect of internal model drift. We note that other methods of correction (e.g., quadratic or cubic detrending, or subtracting the linear drift over a $150-y r$ period) can yield different drift estimates in some models (e.g., Sen Gupta et al.2013). However, as much of our analysis involves multimodel means, we apply the same correction method to all models. We follow the recommendation of Sen Gupta 
TABLE 1. List of CMIP5 models used in this study. Asterisks indicate SIGNEG models, and plus signs indicate SIGPOS models. (Expansions of acronyms are available online at http://www.ametsoc.org/PubsAcronymList.)

\begin{tabular}{|c|c|c|}
\hline Group & Model & Institution \\
\hline \multirow[t]{5}{*}{ SIGNON } & ACCESS1.3 & $\begin{array}{l}\text { Commonwealth Scientific and Industrial Research Organisation } \\
\text { (CSIRO) and Bureau of Meteorology (BoM), Australia }\end{array}$ \\
\hline & BCC_CSM1.1 & Beijing Climate Center, China Meteorological Administration, China \\
\hline & BNU-ESM & College of Global Change and Earth System Science, Beijing Normal University, China \\
\hline & NorESM1-M & Norwegian Climate Centre, Norway \\
\hline & CESM1-BGC & National Science Foundation, U.S. Department of Energy, and NCAR, United States \\
\hline \multirow[t]{5}{*}{ SIGPOS } & $\mathrm{GFDL} \mathrm{CM}^{+}$ & NOAA/Geophysical Fluid Dynamics Laboratory, United States \\
\hline & GFDL-ESM2G $^{+}$ & \\
\hline & GFDL-ESM2M $^{+}$ & \\
\hline & IPSL-CM5A-LR ${ }^{+}$ & Institute Pierre-Simon Laplace, France \\
\hline & 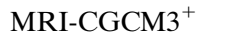 & Meteorological Research Institute, Japan \\
\hline \multirow[t]{12}{*}{ SIGNEG } & ACCESS1.0* & CSIRO and BoM, Australia \\
\hline & CSIRO Mk3.6.0* & CSIRO, Australia \\
\hline & CSIRO Mk3L-1.2* & \\
\hline & FGOALS-s2* & LASG, Institute of Atmospheric Physics, Chinese Academy of Sciences, China \\
\hline & FIO-ESM* & First Institute of Oceanography, China \\
\hline & MIROC5* & $\begin{array}{l}\text { Atmosphere and Ocean Research Institute (The University of Tokyo), } \\
\text { National Institute for Environmental Studies, and Japan Agency for } \\
\text { Marine-Earth Science and Technology, Japan }\end{array}$ \\
\hline & MPI-ESM-LR* & Max Planck Institute for Meteorology, Germany \\
\hline & MPI-ESM-MR* & \\
\hline & MPI-ESM-P* & \\
\hline & CanESM2* & Canadian Centre for Climate Modelling and Analysis, Canada \\
\hline & CMCC-CMS* & Centro Euro-Mediterraneo per I Cambiamenti Climatici, Italy \\
\hline & CNRM-CM5* & Centre National de Recherches Météorologiques, Météo-France, France \\
\hline
\end{tabular}

et al. (2013) of using long portions of the simulations (i.e., $>100-150 \mathrm{yr}$ ) to estimate the linear drift. Table 1 lists the models used in this study.

To identify regions where the contribution of decadal variability to total variability in the subsurface is significant, we analyzed temperatures at $300 \mathrm{~m}$ (T300). This depth encompasses the mixed layer in the Tasman Sea, which varies seasonally from approximately 50 to $200 \mathrm{~m}$ (Rahmstorf 1992; Tilburg et al. 2002). Power and Colman (2006) showed that the vertically averaged temperatures from 0 to $300 \mathrm{~m}$ in a particular coupled model exhibited significant and predictable decadal variability. The authors also found some modest lagged association between $310-\mathrm{m}$ temperatures in the South Pacific and SST in the equatorial Pacific. In Fig. 1, we show the multimodel mean of the ratio of variances of 10 -yr running means $\mathrm{T} 300_{\mathrm{dec}}$ to annual means $\mathrm{T} 300_{\mathrm{ann}}$, that is, the mean of $\operatorname{var}\left(\mathrm{T} 300_{\mathrm{dec}}\right) / \operatorname{var}\left(\mathrm{T} 300_{\mathrm{ann}}\right)$ for each individual model. Equivalent figures for surface temperature and precipitation are provided in the online supplemental material. Ten regions were identified, as shown in Fig. 1. For each region, we then constructed time series using spatially averaged T300 values from each region. Each time series was correlated with surface temperatures (TS) at each grid point globally, at up to a 10-yr lead-lag. Six regions, the Arctic (region 1), tropical Atlantic (regions 3 and 4), Indian Ocean (region 5), and Antarctica (regions 8 and 10), show very weak or no significant correlation between the regional T300 and global TS (figure not shown)

Two hot spots in the South Pacific (regions 7 and 9) show weak correlations with TS in other regions (figure not shown). Region 7, across the South Pacific between New Zealand and the South American coast (Fig. 1), shows weak correlations with TS in the tropical and South Pacific when TS leads T300 by $0-5$ yr. Region 9 , between $180^{\circ}$ and $220^{\circ} \mathrm{E}$ just north of the Ross Sea, shows weak correlation in some parts of the Southern Ocean when TS leads T300 by $0-5$ yr. Previous studies have investigated the drivers of decadal variability in these regions (O'Kane et al. 2013, 2014). Subtropical storm tracks coinciding with regions 6,7 , and 9 are associated with nonlinear baroclinic disturbances driven by large-scale winds across the South Pacific (O'Kane et al. 2014). Additionally, O'Kane et al. (2013) identified the low-frequency South Pacific Intrinsic Mode in region 9, which is driven predominantly by baroclinic instabilities and may be enhanced by atmospheric variability associated with ENSO and the southern annular mode (SAM).

In the two remaining regions, the North Pacific (region 2) and the Tasman Sea (region 6), there is a stronger, more persistent, and more widespread correlation between 


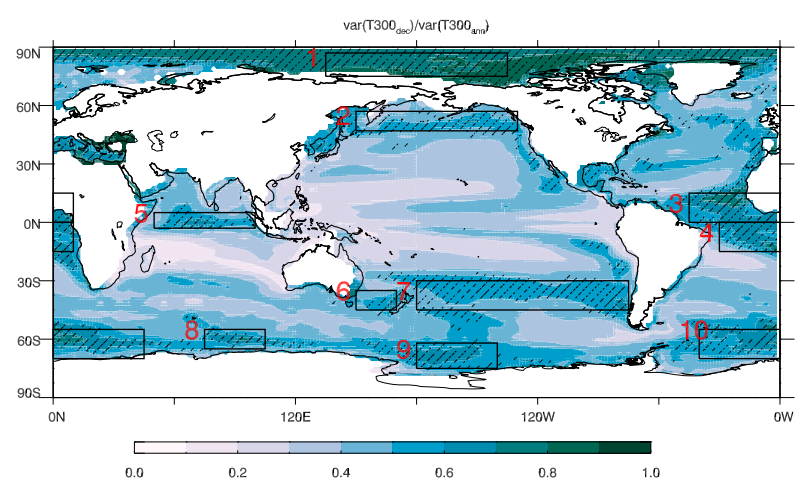

FIG. 1. Multimodel mean of $R=\operatorname{var}\left(\mathrm{T} 300_{\mathrm{dec}}\right) / \mathrm{var}\left(\mathrm{T} 300_{\mathrm{ann}}\right)$ from CMIP5 preindustrial control runs, where $\operatorname{var}\left(\mathrm{T} 300_{\mathrm{dec}}\right)$ is the variance of 10-yr running means of the temperature at $300 \mathrm{~m}$, and $\operatorname{var}\left(\mathrm{T} 300_{\mathrm{ann}}\right)$ is the variance of annual means of the temperature at $300 \mathrm{~m}$. This gives the fraction of variability in 300-m temperature occurring on decadal time scales. Stippling indicates regions where at least $70 \%$ of models have $R>0.4$. Ten "hot spots" that exhibit the largest amount of decadal variability are marked and labeled.

T300 and TS. Figure 2 shows correlations between TS and T300 for region 2 (Figs. 2a-d) and region 6 (Figs. 2e,f) at lags of $-5,-3,3$, and $5 \mathrm{yr}$. Negative lag values indicate that TS leads T300. SSTs in the tropical and North Pacific correlate strongly with T300 in the North Pacific up to $5 \mathrm{yr}$ ahead (Fig. 2a). Meanwhile, the Tasman Sea subsurface temperatures show significant correlations with TS in the Southern Ocean and the Pacific, as far north as approximately $80^{\circ} \mathrm{N}$, at similar lead times. Over the Pacific, correlation maps for both region 2 and 6 exhibit an IPO-like pattern, indicating that the phase of the IPO may impact the T300-TS relationship over the Pacific. When T300 leads TS, however, only the Tasman Sea subsurface temperatures display a high level of model agreement on the sign of the correlations with TS over large regions, specifically in the Southern Ocean and Antarctica. For the remainder of this study, we therefore focus on the Tasman Sea (region 6), examining the correlations between T300 and surface temperature, precipitation, wind stress curl, and subsurface currents in the Southern Hemisphere.

\section{T300, surface temperature, and precipitation in the Southern Hemisphere}

We present correlations between T300 in the SthTas and the two potentially predictable variables of interest, surface temperature and precipitation (PR), at various lags and latitudinal bands in the Southern Hemisphere (Fig. 3), with negative lag $\tau$ indicating surface temperature or precipitation leading T300. The 5\% statistical significance level is calculated using the effective number of degrees of freedom for two autocorrelated time series (e.g., Chelton 1984; Pyper and Peterman 1998).
In the South Pacific, the MMM correlation pattern for T300 in the southern Tasman Sea and surface temperatures at $\tau \leq 0$ resembles a negative IPO phase (Fig. 2), indicating that the subsurface temperature variations in the SthTas may be modulated by the IPO, or that the correlation between TS and T300 is stronger during a particular phase of the IPO (e.g., Goodwin et al. 2006; Holbrook et al. 2011). For $\tau \geq 0$, T300 correlates positively with TS in regions of the Southern Ocean and Antarctica up to several years ahead.

In the $35^{\circ}-50^{\circ} \mathrm{S}$ band (Fig. 3a), which encompasses the SthTas, there is a significant MMM correlation between T300 and surface temperature at $-7 \leq \tau \leq 3 \mathrm{yr}$. Although there is a considerable spread among individual models, all models agree on the sign of the correlation for $\tau \leq 0$, and all but one of the models agree on the sign of the correlation for $\tau \geq 0$. This indicates a robust, persistent relationship between surface and subsurface temperature in the SthTas region, where the surface temperature influences T300 up to $7 \mathrm{yr}$ later, and T300 in turn exerts a weaker, but still significant, influence on surface temperature up to 3 yr later. Farther south, in the $50^{\circ}-65^{\circ} \mathrm{S}$ and $65^{\circ}-90^{\circ} \mathrm{S}$ bands (Figs. 3b,c), there is a much weaker MMM correlation between T300 and surface temperature for $\tau \leq 0$. There is also very little model agreement on the sign of the correlation for $\tau \leq 0$. For $\tau \geq 0$, on the other hand, there is a significant correlation between T300 and surface temperature at positive lead times up to $\tau=2 \mathrm{yr}$. This indicates that while the surface temperature at the $50^{\circ}-65^{\circ} \mathrm{S}$ and $65^{\circ}-90^{\circ} \mathrm{S}$ bands does not drive T300 in the SthTas, variations in T300 are coherent with changes in surface temperature farther south up to $2 \mathrm{yr}$ ahead, with the relationship weakening in going farther south.

The other potentially predictable variable of interest is precipitation. The T300-precipitation correlations for the latitude bands $35^{\circ}-50^{\circ} \mathrm{S}, 50^{\circ}-65^{\circ} \mathrm{S}$, and $65^{\circ}-90^{\circ} \mathrm{S}$ are shown in Figs. $3 \mathrm{~d}-\mathrm{f}$. In the $35^{\circ}-50^{\circ} \mathrm{S}$ band that encompasses the SthTas, the mean correlation shows a significant anticorrelation between precipitation and T300 for $\tau \leq 0$, and a smaller positive correlation for $1 \leq \tau \leq 5 \mathrm{yr}$. While more than $85 \%$ of the models have a significant correlation for $\tau \leq 0$, less than half the models show a significant correlation for $\tau \geq 0$. In the $50^{\circ}-65^{\circ} \mathrm{S}$ band (Fig. $3 \mathrm{e}$ ), the mean correlation switches sign for $\tau \leq 0$ but remains positive for $\tau \geq 0$. Again, $90 \%$ of models agree on a significant and positive correlation for $\tau \leq 0$, but there is a large amount of disagreement on the sign and degree of correlation for $\tau \geq 0$. Over Antarctica, however, in the $65^{\circ}-90^{\circ} \mathrm{S}$ band (Fig. 3f), there is a significant positive mean correlation at positive $\tau$ values, with $50 \%$ of the 

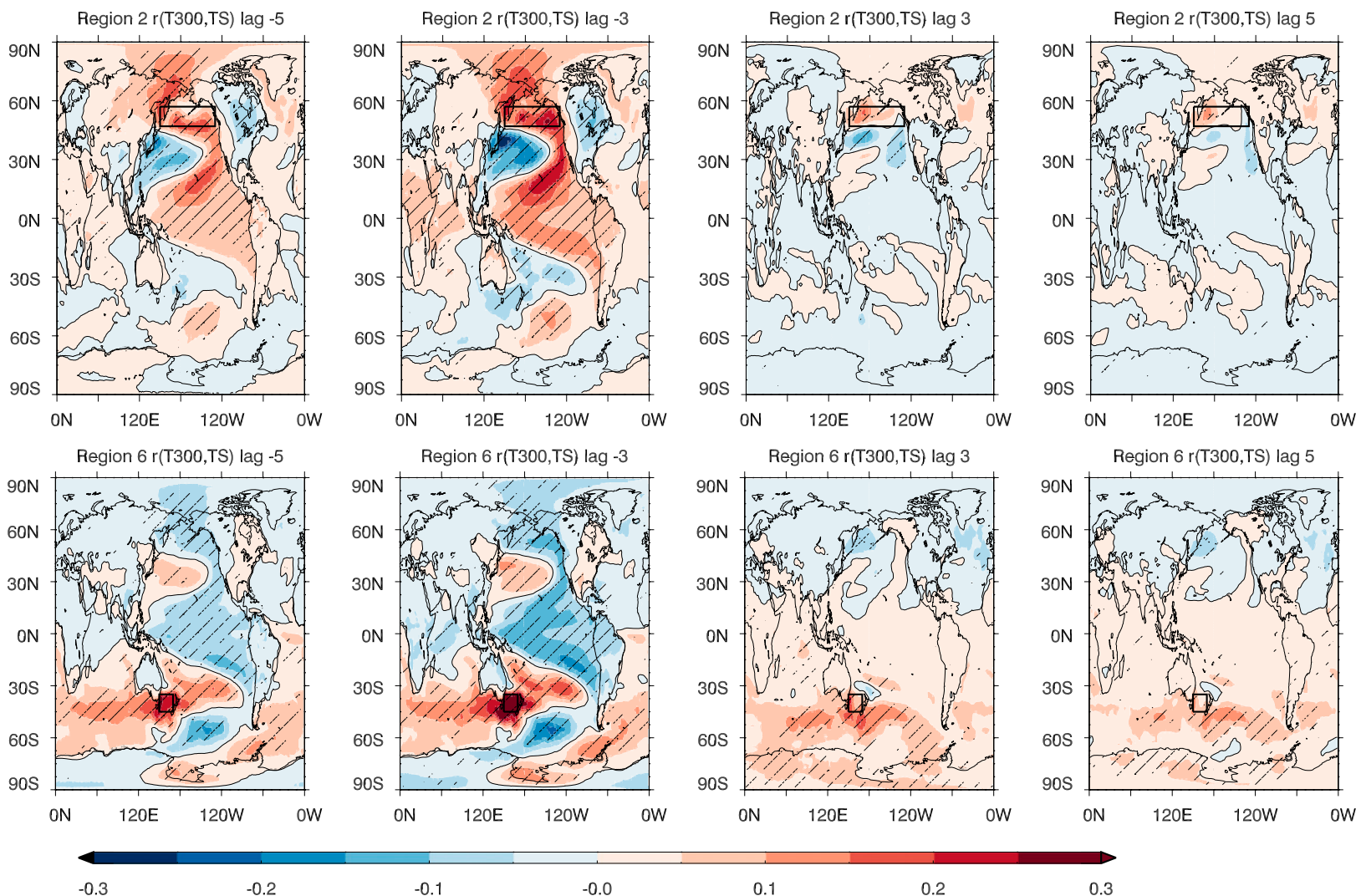

$-0.3$

$-0.2$

$-0.1$

0.1

0.2

0.3

FIG. 2. Correlation between annual means of T300, averaged over (top) region 2 (North Pacific) and (bottom) region 6 (southern Tasman Sea), and global TS at each grid point, at lead time $-5 \leq \tau \leq 5 \mathrm{yr}$. Negative $\tau$ indicates that TS leads T300. The multimodel mean of 22 models from the CMIP5 preindustrial control runs is shown. The maps are stippled where more than $80 \%$ of the models agree (i.e., more than 18 models out of a total of 22 models) on the sign of the correlation.

models showing a significant correlation. These figures indicate that in the southern midlatitudes $\left(35^{\circ}-65^{\circ} \mathrm{S}\right)$, the atmospheric drivers of precipitation variability, such as wind stress, can influence T300 almost a decade later. There is some indication in about half the models that T300 influences rainfall several years later in the Southern Hemisphere, although there is a considerable spread in the models that diminishes the MMM correlation. However, all models agree on the sign of the correlation between T300 and Antarctic precipitation at lead times up to $\tau=2 \mathrm{yr}$. A more detailed analysis of the range of modeled correlations is presented in the next section.

An important link between atmospheric precipitation and the subsurface is salinity (e.g., Lukas 2001; Schmitt 2008). A study of internally generated variations in salinity and upper ocean stability in CMIP5 models shows that, like SSTs, variations in salinity occur at decadal time scales at the mid-to-high latitudes (O'Kane et al. 2016). In the subtropical Pacific, salinity plays a role in destabilizing the stratification of the upper ocean (O'Kane et al. 2016). We do not analyze salinity in this study, but we note that variations in salinity and precipitation are closely linked.

\section{The drivers of subsurface variability in the Tasman Sea}

From Fig. 3, it is clear that the relationship between T300 and surface temperature and precipitation is robust in the $35^{\circ}-50^{\circ} \mathrm{S}$ band, specifically when the surface variables lead T300. Farther south, there is more disagreement amongst models regarding the sign and amplitude of the correlations which leads to a low overall MMM correlation. In this section, we examine the range of modeled behavior and the different drivers of T300 variability in the models. An inspection of individual T300-TS correlation maps at $\tau \leq 0$ shows that the models can be divided into three groups: 1) models that exhibit a widespread significant positive correlation throughout the Southern Hemisphere (SIGPOS, denoted in red in Fig. 3), 2) models that exhibit an IPO-like correlation pattern, with negative correlation in the tropics and over Antarctica 
(a)

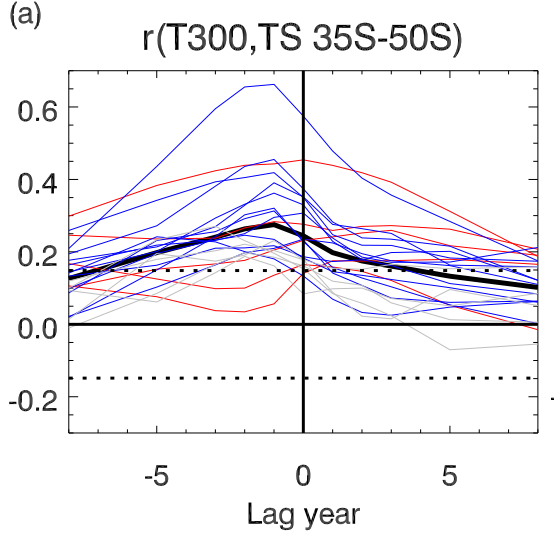

(d)

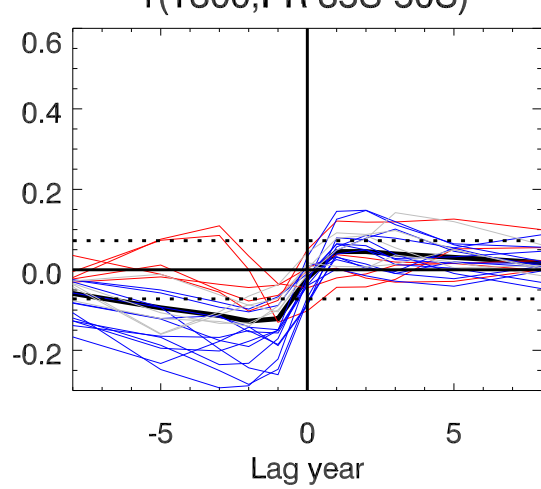

(b)

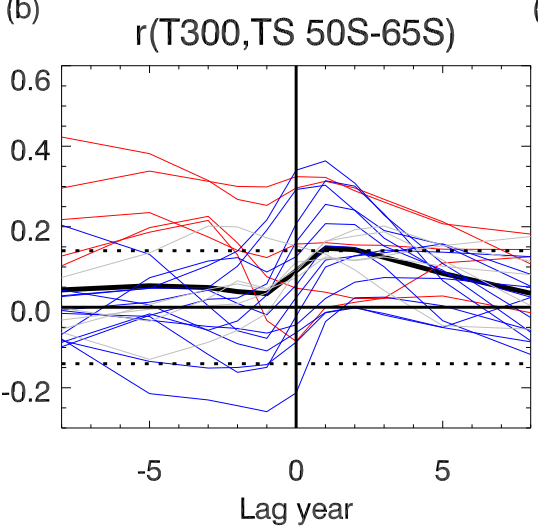

(e)

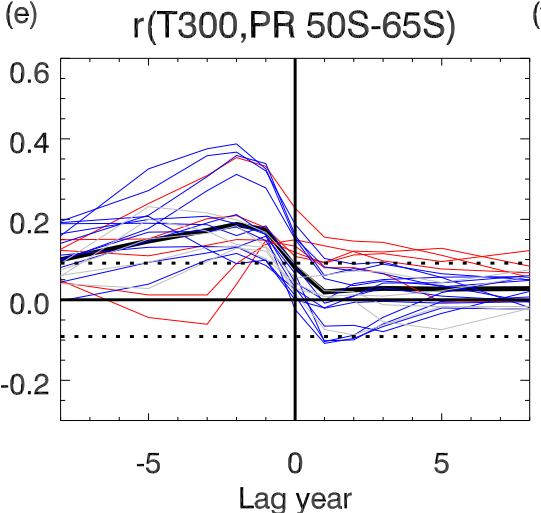

(c) $\quad r($ T300,TS 65S-90S)

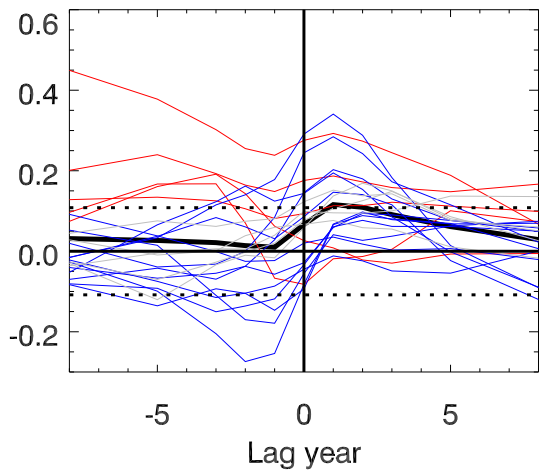

(f)

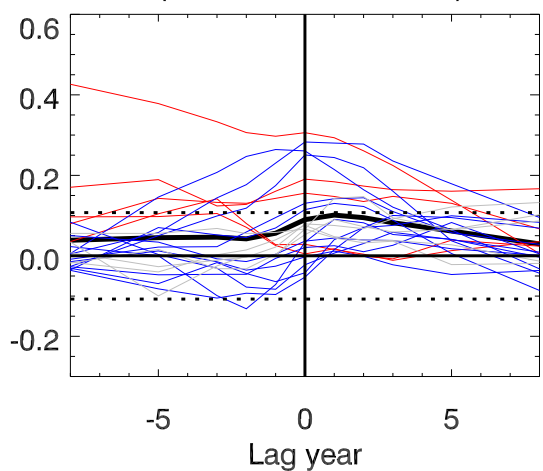

FIG. 3. Correlation between subsurface T300 averaged over the southern Tasman Sea with (a)-(c) TS and (d)-(f) PR zonally averaged over (a),(d) $35^{\circ}-50^{\circ} \mathrm{S}$, (b),(e) $50^{\circ}-65^{\circ} \mathrm{S}$, and (c),(f) $65^{\circ}-90^{\circ} \mathrm{S}$ at lead time $-8 \leq \tau \leq 8 \mathrm{yr}$. Negative $\tau$ indicates that TS and PR lead T300. The thick black lines denote the Fisher weighted multimodel mean correlation of the 22 CMIP5 models, and thin lines show each individual model (red for SIGPOS and blue for SIGNEG models). Thin dotted lines indicate the MMM of 5\% significance levels.

(SIGNEG, denoted in blue in Fig. 3), and 3) models that have weak correlation throughout the Southern Hemisphere (SIGNON, denoted in gray in Fig. 3). Note that there are 12 SIGNEG models, 5 SIGPOS models, and 4 SIGNON models (see notations in Table 1 ). In the rest of this study, we focus only on the SIGPOS and SIGNEG models. Over most of the Southern Hemisphere, the T300 correlates positively with TS in the SIGPOS group, whereas the opposite is true for the SIGNEG group (Fig. 4). For the SIGPOS and SIGNEG groups, the correlation between T300 and TS, PR, wind stress curl (WSC), zonal currents at $300 \mathrm{~m}$ (U300), meridional currents at $300 \mathrm{~m}$ (V300), and net surface heat flux (HF) are shown at lags $-2,0$, and +2 yr (Figs. 4, 5, and 6, respectively).

We first discuss the similarities between the groups of models. For both SIGPOS and SIGNEG models, the pattern of correlation between the WSC and T300 implies that wind stress curl, particularly over the South Pacific, is involved in driving T300 variability. This is shown by statistically significant correlation that is strongest when the wind stress leads T300 by $1-5 \mathrm{yr}$ (e.g., Fig. 4, fourth row from top). The correlation drops to almost zero globally at lag zero and when the WSC lags T300 (e.g., Figs. 5 and 6, fourth row from top). This indicates that while wind stress over the South Pacific is an important driver of T300 variability in the southern Tasman Sea, T300 does not, in turn, influence or remain connected to wind stress variability. This is consistent with previous observation- and model-based studies that have found that the wind stress over the South Pacific plays an important role in driving variability in the Tasman Sea and surrounding regions. Hill et al. (2008, 2011) found that the temperature and salinity changes in the Tasman Sea were correlated with basinwide winds, whereas Sloyan and O'Kane (2015) found that the response of the Tasman Sea to basinwide wind stress curl was determined by nonlinear, dynamical processes.

In both sets of models, the positive wind stress curl anomaly at the latitude of Tasmania at $\tau=-2 \mathrm{yr}$ depicts enhanced Southern Ocean westerly winds to the south of SthTas and weakened subtropical westerlies to the 
SIGPOS
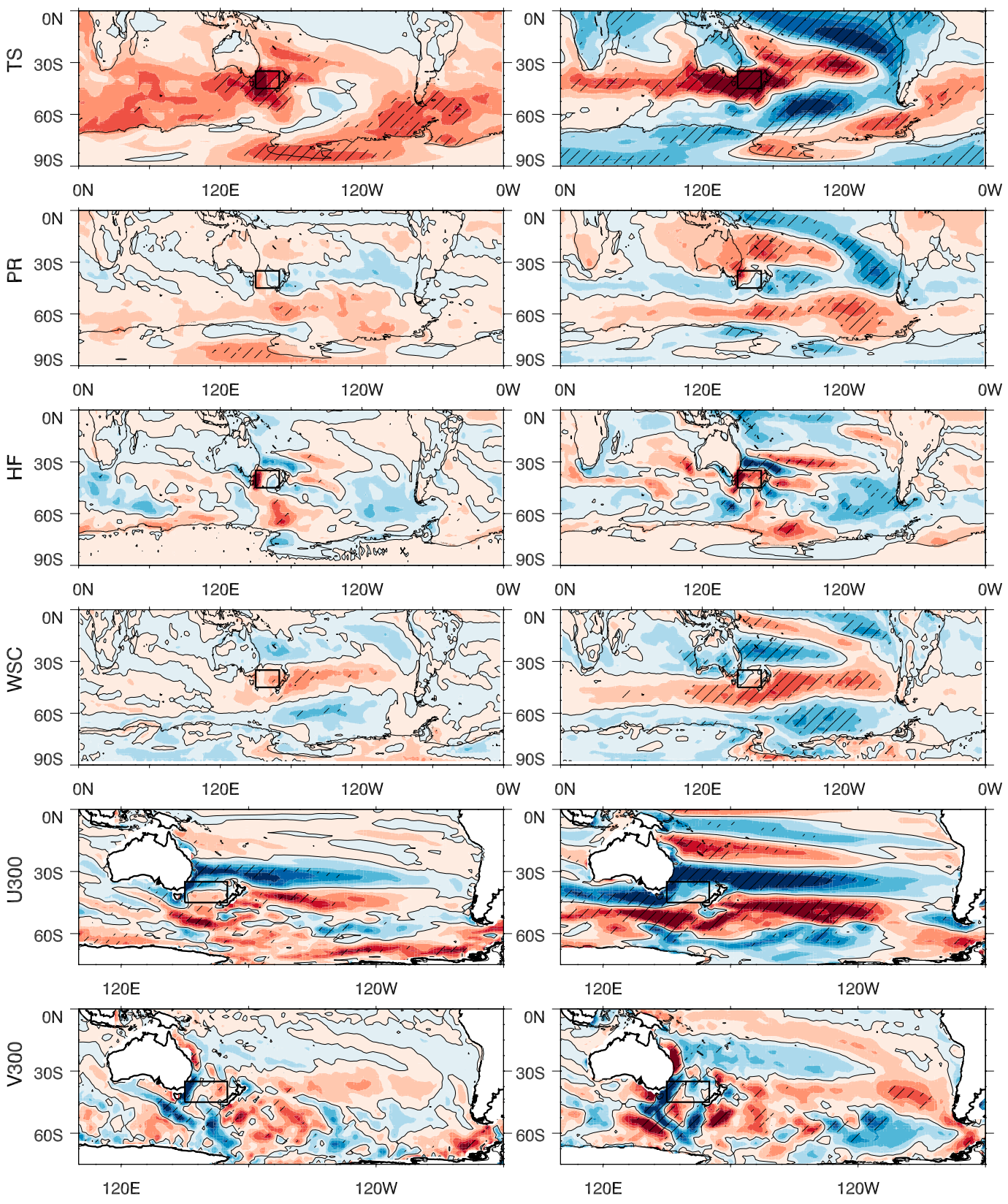

$-0.0$

0.1

0.2

0.3

FIG. 4. Correlation between annual means of T300 and (top)-(bottom) TS, PR, HF, WSC, U300, and V300, at a lead time of $\tau=-2 \mathrm{yr}$. (left) The multimodel mean of the SIGPOS group, and (right) The multimodel mean of the SIGNEG group (see text for details). Maps are stippled where more than $70 \%$ of models in each group show a significant correlation at the $5 \%$ level.

north around the Tasman Front. The impact can be seen in the subsurface ocean circulation whereby the correlation pattern for U300 (which is positive eastward) consistently shows westward and eastward current anomalies to the north and south of SthTas (Figs. 4 and 5, bottom). This indicates an anticyclonic gyre anomaly, which remains coherent with $\mathrm{T} 300$ up to $5 \mathrm{yr}$ later (e.g., Fig. 6, fifth row from top). 

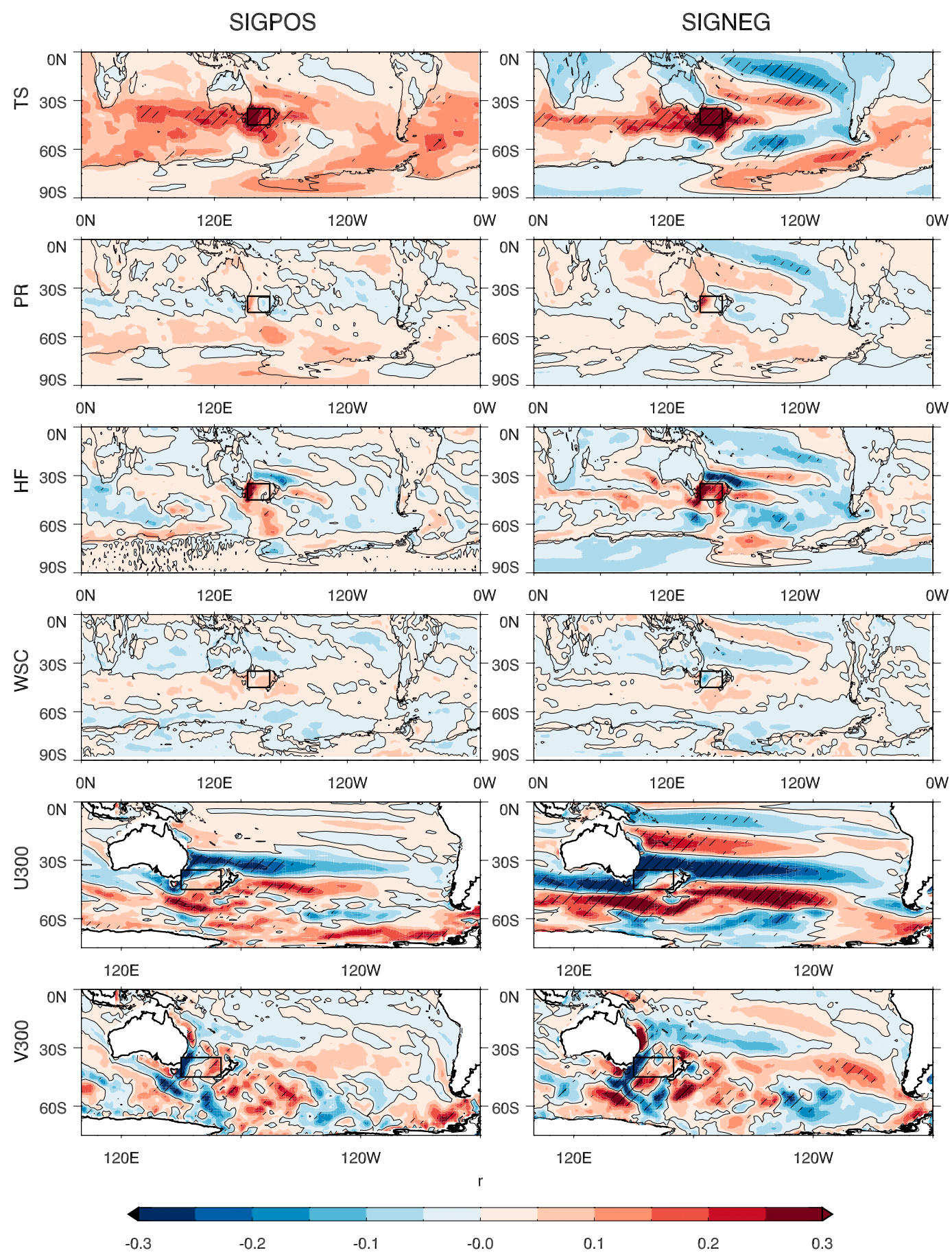

FIG. 5. As in Fig. 4, but at zero lag.

Off the east coast of Australia, north of the SthTas, there is an input of heat at the surface (since HF is positive upward) at $\tau \leq 0$. Concurrently, the anomalous westward current along the Tasman Front supports a stronger southward EAC extension, which provides an advective pathway for this heat into SthTas, leading to SthTas warming at 300-m depth several years later. There is also a negative correlation between HF and T300 in the southeastern Pacific off the South American coast, again indicating an input of heat into the ocean prior to T300 in the SthTas warming, which may then be transported westward into the SthTas via the subtropical gyre circulation. 
SIGPOS

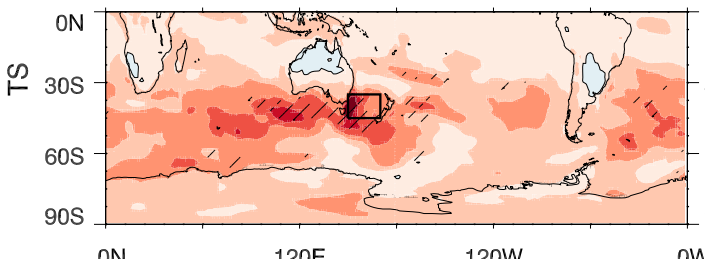

SIGNEG
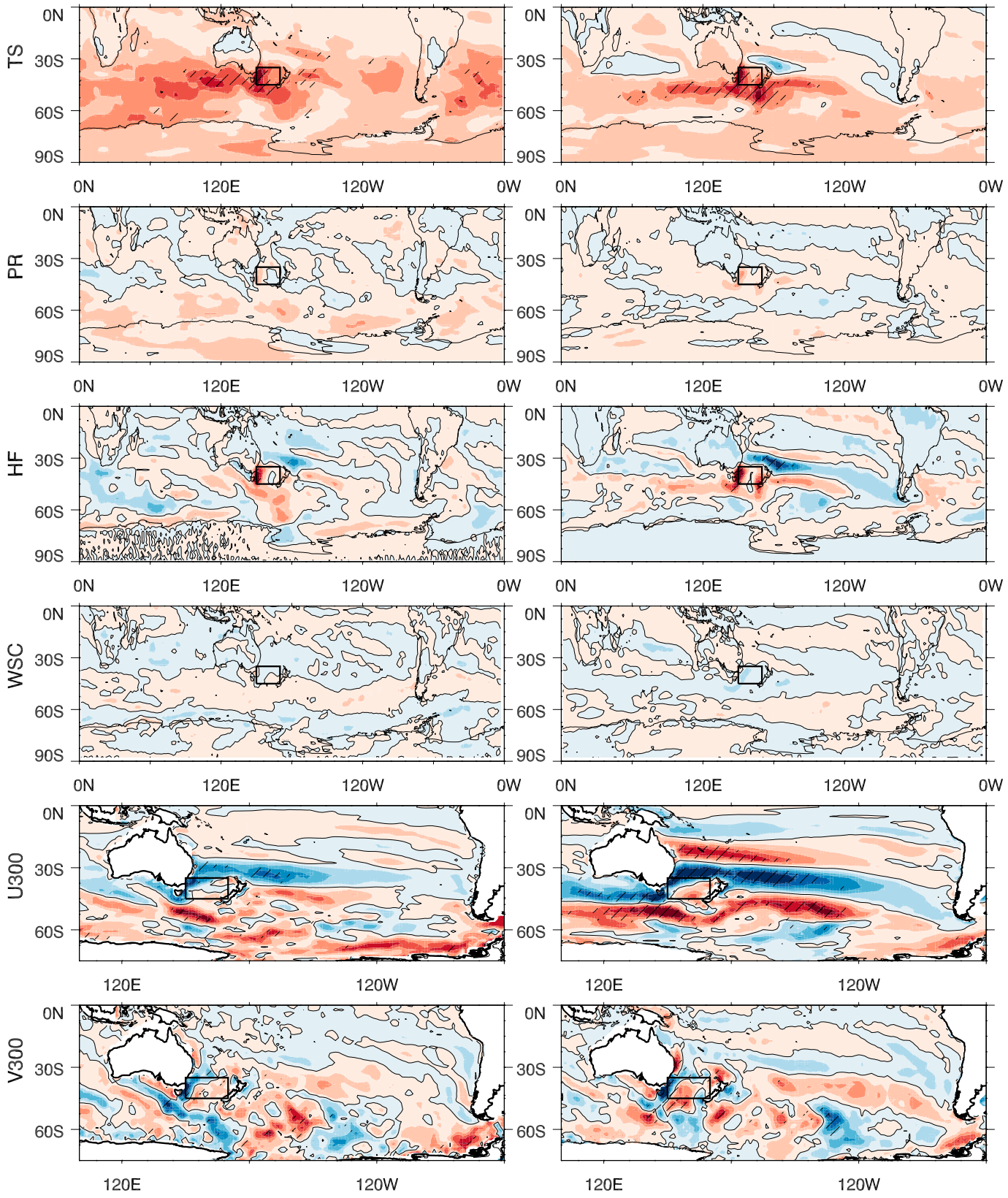

ON

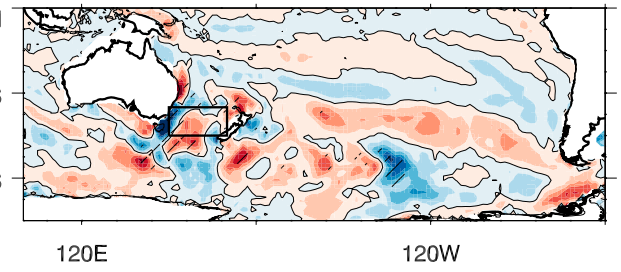

0.2

$-0.1$

$-0.0$

0.1

0.3

FIG. 6. As in Fig. 4, but for a lag of $+2 \mathrm{yr}$.

Despite these similarities, the two groups of models display marked differences. The relationship between T300 and WSC at lag $-2 \mathrm{yr}$ is significant only across the South Pacific basin in the SIGPOS models, with a positive correlation extending southwest from approximately $35^{\circ}-45^{\circ} \mathrm{S}$ off the South American coast to approximately $45^{\circ}-60^{\circ} \mathrm{S}$ south of Australia (Fig. 4, fourth row from top). In the SIGNEG models, on the other hand, the correlation between T300 and WSC is stronger over the tropical Pacific, and the positive response to WSC has a more zonal and circumpolar structure, spanning the entire South Pacific and south Indian Ocean, between approximately $35^{\circ}-55^{\circ} \mathrm{S}$ (Fig. 4 , fourth row from top). 
(a)

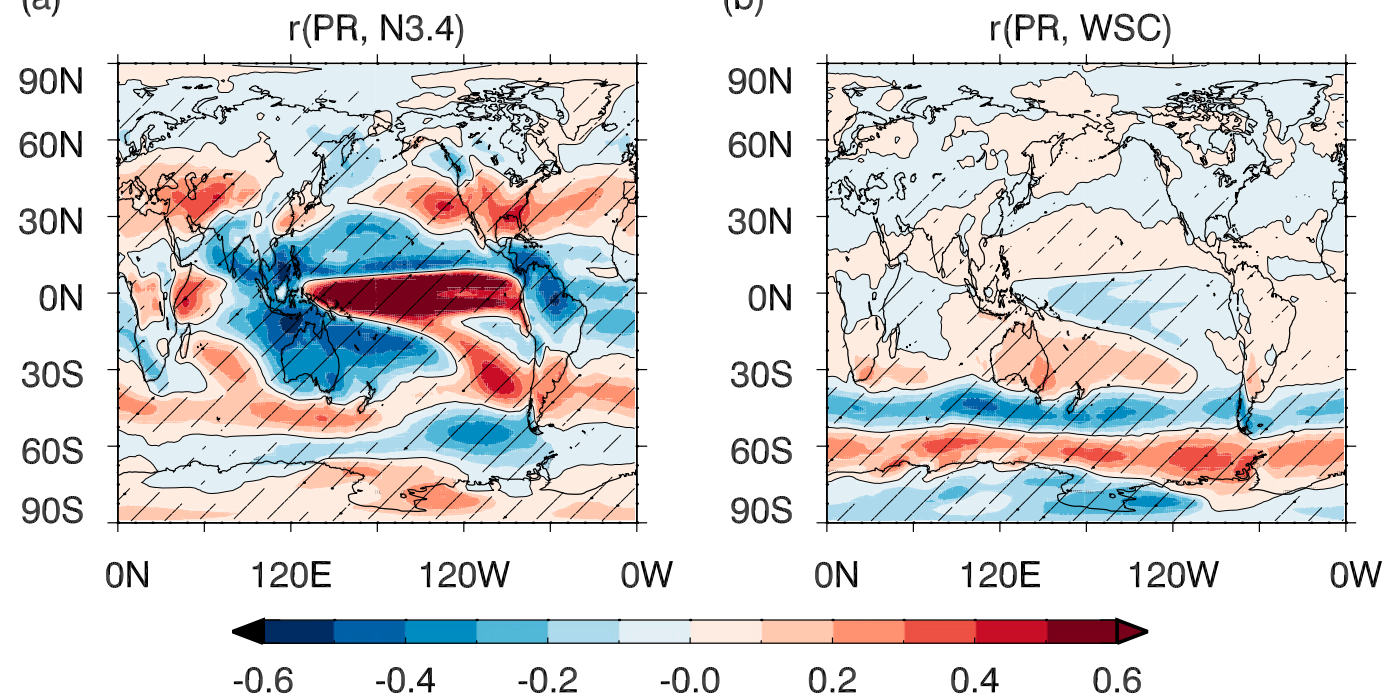

FIG. 7. Correlation between annual means of global precipitation and (a) the Niño-3.4 index, and (b) zonal mean wind stress curl from $45^{\circ}$ to $65^{\circ} \mathrm{S}$. The Fisher weighted multimodel mean of 22 models from the CMIP5 preindustrial control runs is shown. The maps are stippled where more than $80 \%$ of the models agree on the sign of the correlation.

In the tropical Pacific, the stronger response of the ocean to WSC in the SIGNEG models results in stronger anomalous patterns in subsurface currents-a feature that is lacking in the SIGPOS models. In particular, the SIGNEG models show a positive correlation with V300 in the tropical Pacific at lags $\tau \leq 0$ (Figs. 4 and 5, bottom), which implies that heat is transported toward the equator. An additional anticyclonic gyre structure is seen in U300 in the SIGNEG models between $0^{\circ}$ and $30^{\circ} \mathrm{S}$ (Figs. 4-6, fifth row from top), implying more efficient redistribution of heat in this region. The equatorward transport of heat and additional gyre near the equator result in the negative correlation between T300 in the southern Tasman Sea and TS in the equatorial Pacific and parts of the Southern Ocean. In the SIGPOS models, the ocean responds less to wind stress curl variability in the tropics, thus heat from the Southern Ocean remains largely confined to the mid-to-high latitudes, southward of approximately $30^{\circ} \mathrm{S}$.

The SIGPOS and SIGNEG models also exhibit very different correlations between T300 and PR over much of the Southern Hemisphere. As opposed to the SIGPOS models, the SIGNEG models exhibit more statistically significant correlations over the tropical and South Pacific for $\tau \leq 0 \mathrm{yr}$ (e.g., Figs. 4 and 5, second row from top), with a pattern similar to the T300-TS map. Over Antarctica, however, the SIGPOS models exhibit a positive correlation between T300 and PR, whereas the SIGNEG models exhibit a weaker, negative correlation. To further investigate the factors influencing precipitation variability in the models, we correlate the July-June annual means of global precipitation with the DJF Niño-3.4 index (Fig. 7a) and July-June annual means of wind stress curl averaged over $45^{\circ}-65^{\circ} \mathrm{S}$ (Fig. $7 \mathrm{~b}$ ). In the tropical Pacific, precipitation variability is driven primarily by ENSO (Fig. 7a). In the South Pacific, while there is still a significant contribution from ENSO, precipitation has a stronger correlation with the $45^{\circ}-65^{\circ} \mathrm{S}$ averaged wind stress curl (Fig. 7b), which is expected given the association of storm tracks with the meridional position of the Southern Ocean winds. Therefore the SIGNEG models, which exhibit a stronger T300 response to surface temperature and wind stress in the tropical and South Pacific, also exhibit a stronger correlation with precipitation in this region.

The extent to which T300 can provide multiyear predictive capability can be gauged from Fig. 6, which shows that at $\tau=+2 \mathrm{yr}$ T300 is positively and significantly correlated with TS in the Southern Ocean, south of Australia, for both groups of models. The SIGPOS models exhibit marginally stronger and more widespread correlation extending across the south Indian Ocean and into the South Atlantic. This is likely due to the more efficient heat transport toward the equator in the SIGNEG group. The correlation between T300 and PR at most grid points in the Southern Hemisphere is relatively weak in all models. However, as seen in Fig. 3, the correlation between T300, TS, and PR at positive lead times is higher when considering the zonal means of 

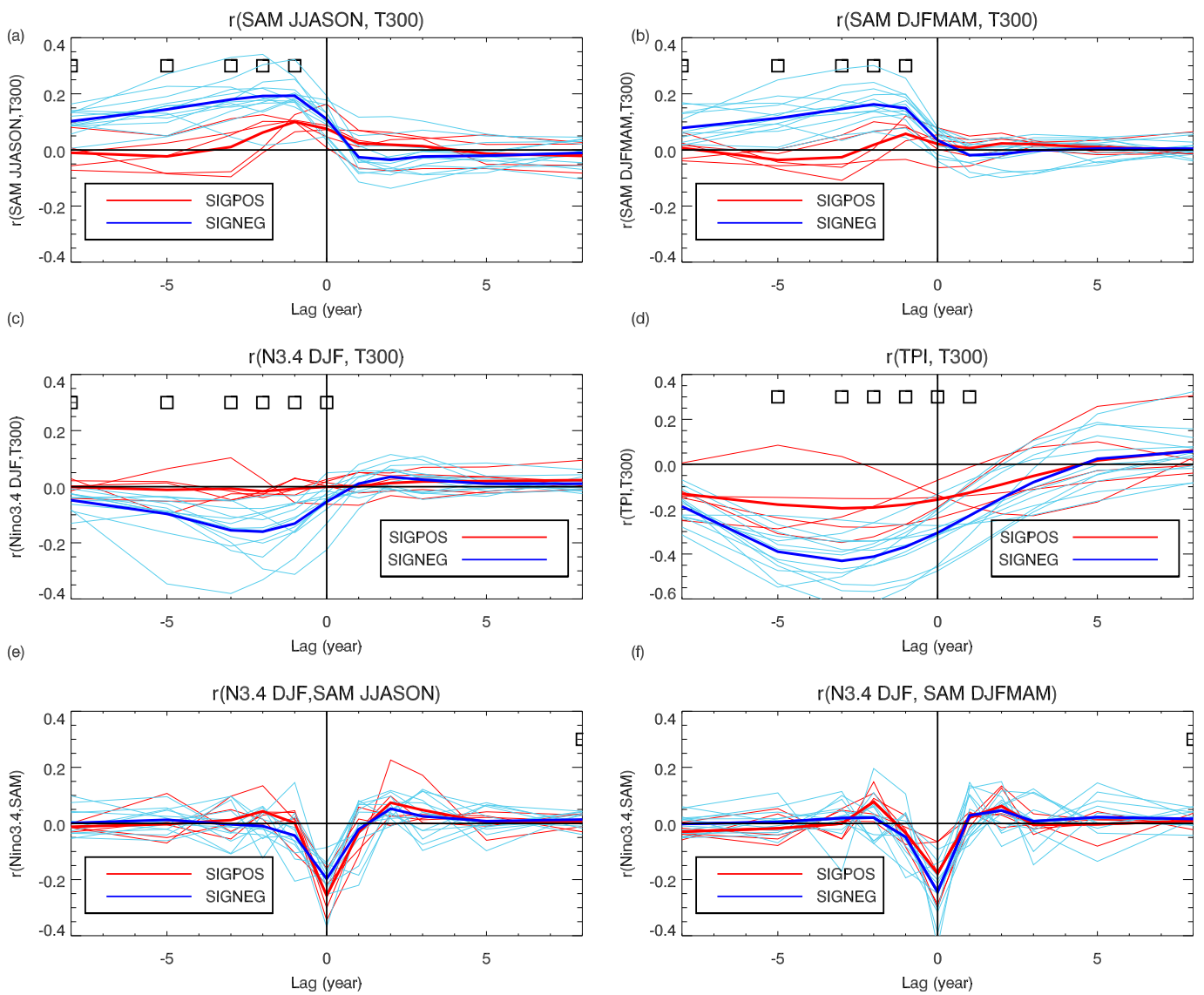

FIG. 8. Correlation between T300 and the (a) JJASON SAM index, (b) DJFMAM SAM index, (c) DJF Niño-3.4 index, and (d) TPI index, and correlation between the DJF Niño-3.4 index and the (e) JJASON SAM index and (f) DJFMAM SAM index for lags $-8 \leq \tau \leq 8 \mathrm{yr}$. Thick lines indicate the multimodel mean of the SIGPOS (red) and SIGNEG (blue) groups, and thin lines indicate individual models. Squares indicate lags at which the SIGPOS and SIGNEG groups are significantly different at the $5 \%$ level.

TS and PR, and statistically significant for TS between $50^{\circ}-65^{\circ}$ and $65^{\circ}-90^{\circ} \mathrm{S}$ (Figs. $3 \mathrm{~b}, \mathrm{c}$ ).

\section{Links with ENSO, SAM, and the IPO}

The significant correlations between T300, TS, and wind stress in the Pacific imply that variability in T300 may be influenced by large-scale climate modes such as ENSO and SAM, which are dominant on multiyear time scales, and by the IPO on longer time scales. We explore this possible link in the SIGPOS and SIGNEG models using cross-correlation analysis between T300 and the climate indices (Figs. 8a-d). We utilize the SAM index, the difference between the zonal mean sea level pressures at $40^{\circ}$ and $65^{\circ} \mathrm{S}$ (Gong and Wang 1999), averaged over austral winter to spring [June-November (JJASON)] and austral summer to autumn [December-May (DJFMAM)], the DJF Niño-3.4 index, and the tripole index (TPI) which was developed by Henley et al. (2015) as a measure of the IPO. We use a 13-yr filtered TPI, which is defined as the difference in SST anomalies from the central equatorial Pacific, and the average of the northwest and southwest Pacific regions.

Most of the SIGNEG models (MMM in thick blue lines, individual models in thin blue lines) exhibit a statistically significant correlation between T300 and the SAM and Niño-3.4 indices at negative $\tau$ values, indicating that T300 variability is influenced by these processes (Figs. 8a-c). On the other hand, four out of five SIGPOS models show no correlation with the Niño3.4 index (Fig. 8c), and all exhibit a weak correlation with the SAM indices (Figs. 8a,b). The differences between the two groups are most striking and statistically significant at negative lags (as marked with squares in Fig. 8a). The correlation between T300 and TPI is higher as both vary on decadal time scales (Fig. 8d), with the SIGNEG models exhibiting a stronger correlation at $-3 \leq \tau \leq 0 \mathrm{yr}$. 


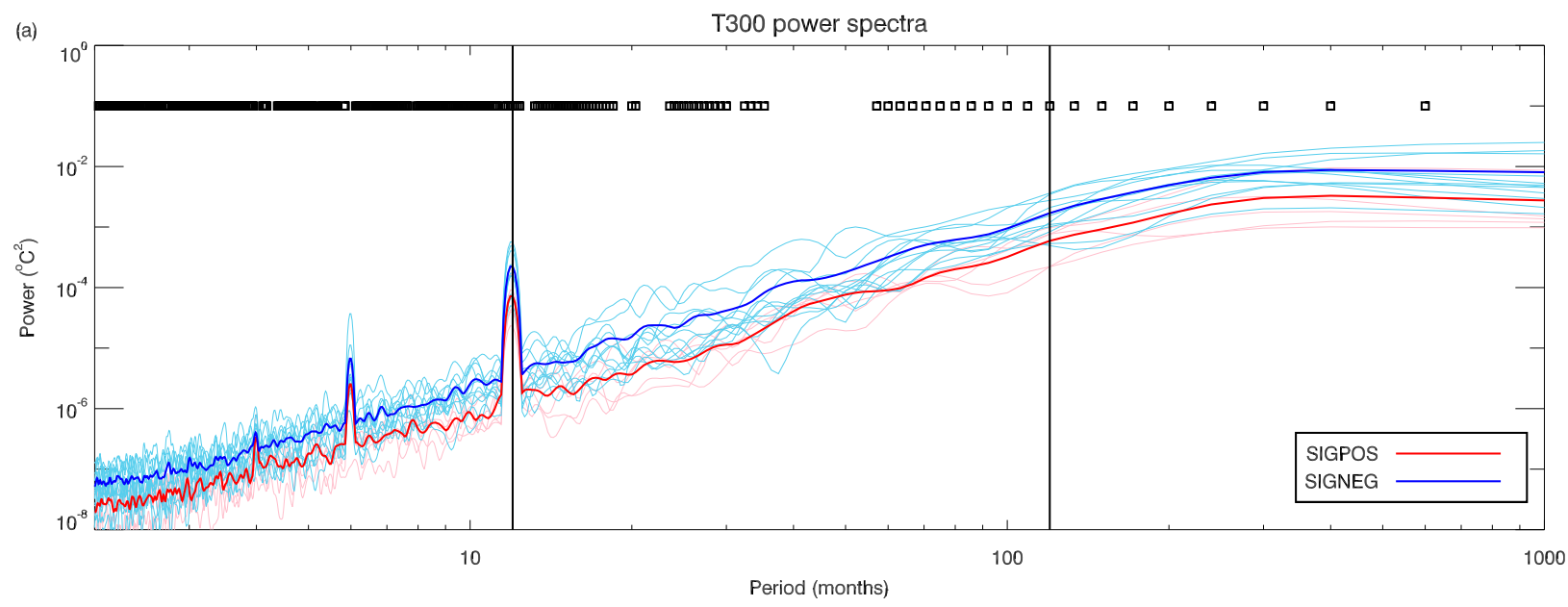

(b)

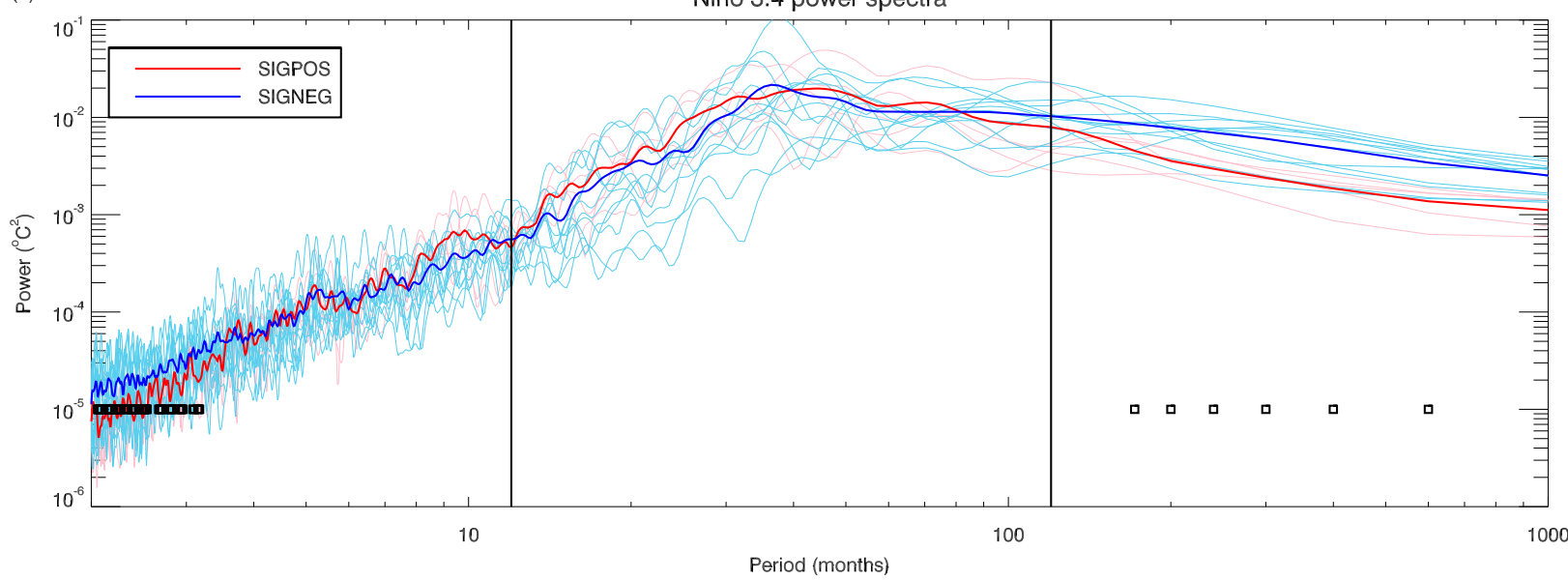

FIG. 9. Power spectra of (a) T300 in the southern Tasman Sea and (b) Niño 3.4 indices for SIGPOS (red) and SIGNEG (blue) groups. Thick lines indicate the multimodel mean of the SIGPOS and SIGNEG groups, and thin lines indicate individual models. Vertical lines indicate 1- and 10-yr periods. Squares indicate periods at which SIGPOS and SIGNEG groups are significantly different at the $5 \%$ level.

Although the two groups have significantly different oceanic responses to ENSO and SAM, the Niño-3.4-SAM index correlations are similar (Figs. 8e,f). This indicates that the differences in the two groups stem primarily from the ocean component's response to wind stress curl and SST changes rather than from a difference in atmospheric teleconnections.

To further understand the lack of T300-Niño-3.4 correlation in the SIGPOS models, we examine the power spectra of the T300 and the Niño-3.4 indices in the SIGPOS and SIGNEG models (Fig. 9). Figure 9a shows that T300 in both groups of models exhibit very similar spectral characteristics in variability that peak over multidecadal time scales. However, the SIGPOS group has significantly weaker variability. Furthermore, Fig. 9b shows that the Niño-3.4 indices for both groups have similar power spectra at interannual time scales, but the SIGPOS group has significantly less power at multidecadal time scales. This means that the ENSO in the SIGPOS models lack multidecadal variability-the dominant time scale in T300 variability (Fig. 9a)-thus explaining the weaker correlation between T300 and Niño-3.4 in the SIGPOS models (Fig. 8c). This is also supported by the weak correlations with TPI (Fig. 8d). Power spectra of the SAM and TPI indices are shown in the supplemental material. While the power spectra of the SAM indices are similar for both groups, the TPI indices in the SIGPOS group also exhibit significantly less power at decadal time scales.

Finally, we test the hypothesis that the phase of the IPO influences the impact of ENSO on the Tasman Sea, namely that ENSO has a larger impact during negative IPO phases (Goodwin et al. 2006; Holbrook et al. 2011). For each model, we calculate the 13-yr low-pass-filtered tripole index. For each positive or negative phase of the TPI lasting at least $9 \mathrm{yr}$, we calculate the correlation 
between T300 and the Niño-3.4 index during those years, at lags from -2 to $+2 \mathrm{yr}$ (not shown). We found no significant differences in the strength of the correlations for positive or negative phases of the TPI, indicating that in the models the impact of ENSO on the Tasman Sea is independent of the IPO phase.

\section{Summary and discussion}

In this study, we identified several oceanic "hot spots" that exhibit a large fraction of decadal variability (relative to interannual variability) in the CMIP5 preindustrial control simulations. Of these, only two regions in the Pacific displayed a statistically significant correlation with surface temperatures elsewhere. We focused on the Tasman Sea, where the subsurface temperatures correlate significantly with surface temperatures across the Pacific and Southern Oceans up to $5 \mathrm{yr}$ prior and 2-3 yr later. This relationship appears to be driven predominantly by basinwide surface wind stress anomalies, which drive a response in the South Pacific subtropical gyre. The anomalous subsurface currents transport atmospheric heat content from the southeastern Pacific and the Tasman Front into the SthTas region. The importance of surface wind stresses in driving changes in the Tasman Sea temperature is consistent with earlier research (Hill et al. 2008, 2011). However, we note that Sloyan and O'Kane (2015) showed that this relationship is nonlinear, and that dynamical responses to wind stress variability also play an important role in driving Tasman Sea variability. Our results are also consistent with the work of Frankignoul and Hasselmann (1977), who showed that high-frequency white noise in atmospheric variables such as surface heat flux and wind stress can drive a reddened, lowfrequency response in sea surface temperatures and the thermocline.

A closer examination of the individual models shows that 5 models display a statistically significant positive correlation between subsurface and surface temperatures in the mid-to-high southern latitudes (the SIGPOS group), while 12 models display a mostly negative or IPO-like correlation pattern (the SIGNEG group). A number of factors play a part in causing this difference. First, the subsurface variability in the SIGNEG models is significantly stronger than in the SIGPOS models. This is associated with a stronger response to wind stress curl in the tropical Pacific than in the SIGPOS group, which generates an anticyclonic gyre and stronger meridional currents that transport heat from the Southern Ocean equatorward. In the SIGPOS models, the heat from the Southern Ocean is largely confined to the midto-high latitudes, resulting in a more persistent and widespread correlation between T300 and TS at positive lead times and higher potential predictability in this region. Second, in the SIGNEG models, the Niño-3.4 indices display significantly stronger variability at multidecadal time scales. The SIGNEG models have a strong correlation with the TPI at negative lead times, indicating that IPO-driven changes in the sea surface temperature in the Pacific also play a role in modulating the T300-TS relationship in these models.

The subsurface variability in the southern Tasman Sea is coherent with surface temperature changes more broadly across the Pacific and it propagates southward over the next several years, providing a predictive capability in surface temperatures south of $35^{\circ} \mathrm{S}$. In the SIGPOS models, the southern Tasman Sea subsurface temperatures are coherent with surface temperatures over a larger fraction of the Southern Hemisphere, and for longer. This is likely due to the SIGPOS models exhibiting weaker subsurface variability, as well as having a weaker response to variability in the tropics, enabling heat in the Southern Ocean to remain confined to the Southern Hemisphere for longer.

A full analysis of the differences in the physical mechanisms driving the SIGPOS and SIGNEG model behavior is outside the scope of this study. However, some possibilities include differences in how the models simulate tropical climate variability, such as ENSO and the IPO, and how they handle cloud dynamics. This, can influence convective activities in the tropics and consequently the simulation of ENSO (Bellenger et al. 2014), and at high latitudes cloud-dynamics biases can affect the atmospheric radiative balance (Grise and Polvani 2014).

Three out of the five SIGPOS models belong to the GFDL group of climate models, which share the same atmospheric component [GFDL CM3 uses the version 3 of the GFDL Atmospheric Model (AM3), whereas GFDLESM2M and GFDL-ESM2G use AM2; Griffies et al. 2011; Dunne et al. 2012]. The other models in the SIGPOS group are the IPSL-CM5A-LR, which uses LMDZ (Dufresne et al. 2013), and the MRI-CGCM3 (Yukimoto et al. 2012). A previous analysis of nine atmospheric general circulation models showed that only the AM2 and LMDZ4 provide an accurate representation of negative feedback from cloud albedo and atmospheric transport over the equatorial cold tongue (Sun et al. 2006). However, a separate study (Grise and Polvani 2014) divided CMIP5 coupled models into two groups, one with a more realistic representation of cloud dynamics over the Southern Ocean. This group includes the three GFDL models, MRI-CGCM3, and three models from the SIGNEG group (ACCESS1.0, MRI-CGCM3, and CSIRO Mk3.6.0). The second group comprised IPSLCM5A-LR, three SIGNON models, and three SIGNEG 
models. Additionally, Henley et al. (2017) identified nine CMIP5 coupled models with a well-represented IPO, of which six belong to the SIGNEG group, two to the SIGNON group, and one to SIGPOS. Therefore, while atmospheric radiative feedbacks may play a role in the results presented in this study, a more detailed analysis is required to distinguish the physical mechanisms driving the SIGPOS and SIGNEG models as they do not appear to have a clear-cut distinction when evaluated on a range of processes.

While the maps in Fig. 6 show weak correlation between T300 and precipitation in the Southern Hemisphere at a +2 -yr lag, correlations between T300 and the zonal means of precipitation are larger, especially in the $65^{\circ}-90^{\circ} \mathrm{S}$ band (Fig. 3). For surface temperature, T300 also shows significant MMM correlation with zonal means of TS at all three latitude bands from $35^{\circ}$ to $90^{\circ} \mathrm{S}$ at a +2 -yr lag. We note also that at positive lags, most models $(>80 \%)$ agree on the sign of the T300-TS correlation over most of the Southern Hemisphere, despite the SIGPOS and SIGNEG models having different correlation patterns at negative lags.

Our results are consistent with the potential predictability studies of Boer (2011) and Boer et al. (2013), who found that the potential predictability skill for internally generated variability in the Southern Hemisphere is largest in the Southern Ocean for surface temperature, and largest at high latitudes for precipitation [note that Figs. S1 and S2 in the supplemental material are comparable to Fig. 4 of Boer and Lambert (2008)]. One issue that warrants further study is that the potential predictability on the multiyear to decadal time scale may be seasonally dependent, as temperature and rainfall are influenced by different drivers on seasonal time scales. Future experimental work is planned to further investigate the role of tropical variability on heat transport and its effect on potential predictability in the Southern Hemisphere.

Acknowledgments. The authors thank Michael Grose, Andrew Marshall, Terry O'Kane, and Francois Delage for their detailed reviews of the manuscript. The authors also thank Francois Delage and Harvey Ye for processing some of the CMIP5 data. This research was supported by the Australian Climate Change Science Program (ACCSP) and the National Environmental Science Program (NESP). We acknowledge the World Climate Research Programme's Working Group on Coupled Modelling, which is responsible for CMIP, and we thank the climate modeling groups (listed in Table 1 of this paper) for producing and making available their model output. For CMIP the U.S. Department of Energy's Program for Climate Model Diagnosis and In- tercomparison provides coordinating support and led development of software infrastructure in partnership with the Global Organization for Earth System Science Portals. This research was undertaken with the assistance of resources from the National Computational Infrastructure (NCI), which is supported by the Australian Government.

\section{REFERENCES}

Bellenger, H., E. Guilyardi, J. Leloup, M. Lengaigne, and J. Vialard, 2014: ENSO representation in climate models: From CMIP3 to CMIP5. Climate Dyn., 42, 1999-2018, doi:10.1007/s00382-013-1783-z.

Boer, G. J., 2011: Decadal potential predictability of twenty-first century climate. Climate Dyn., 36, 1119-1133, doi:10.1007/ s00382-010-0747-9.

_ predictability of precipitation and temperature. Geophys. Res. Lett., 35, L05706, doi:10.1029/2008GL033234.

— , V. V. Kharin, and W. J. Merryfield, 2013: Decadal predictability and forecast skill. Climate Dyn., 41, 1817-1833, doi:10.1007/s00382-013-1705-0.

Cai, W., P. H. Whetton, and D. J. Karoly, 2003: The response of the Antarctic Oscillation to increasing and stabilized atmospheric $\mathrm{CO}_{2}$. J. Climate, 16, 1525-1538, doi:10.1175/ 1520-0442-16.10.1525.

Chelton, D. B., 1984: Commentary: Short-term climatic variability in the Northeast Pacific Ocean. The Influence of Ocean Conditions on the Production of Salmonids in the North Pacific, W. Pearcy, Ed., Oregon State University Press, 87-99.

Chikamoto, Y., and Coauthors, 2013: An overview of decadal climate predictability in a multi-model ensemble by climate model MIROC. Climate Dyn., 40, 1201-1222, doi:10.1007/ s00382-012-1351-y.

Dufresne, J., and Coauthors, 2013: Climate change projections using the IPSL-CM5 Earth System Model: From CMIP3 to CMIP5. Climate Dyn., 40, 2123-2165, doi:10.1007/s00382-012-1636-1.

Dunne, J., and Coauthors, 2012: GFDL's ESM2 global coupled climate-carbon Earth system models. Part I: Physical formulation and baseline simulation characteristics. J. Climate, $\mathbf{2 5}$, 6646-6665, doi:10.1175/JCLI-D-11-00560.1.

Flato, G., and Coauthors, 2013: Evaluation of climate models. Climate Change 2013: The Physical Science Basis, T. F. Stocker et al., Eds. Cambridge University Press, 741-882, doi:10.1017/ CBO9781107415324.020.

Frankignoul, C., and K. Hasselmann, 1977: Stochastic climate models, Part II. Application to sea-surface temperature anomalies and thermocline variability. Tellus, 29, 289-305, doi:10.3402/tellusa.v29i4.11362.

Godfrey, J. S., G. R. Cresswell, T. J. Golding, A. F. Pearce, and R. Boyd, 1980: The separation of the East Australian Current. J. Phys. Oceanogr., 10, 430-440, doi:10.1175/1520-0485(1980)010<0430: TSOTEA $>2.0 . \mathrm{CO} ; 2$.

Gong, D., and S. Wang, 1999: Definition of Antarctic oscillation index. Geophys. Res. Lett., 26, 459-462, doi:10.1029/1999GL900003.

Goodwin, I. D., M. A. Stables, and J. Olley, 2006: Wave climate, sediment budget and shoreline alignment evolution of the Iluka-Woody Bay sand barrier, northern NSW, Australia, since $3000 \mathrm{yr}$ BP. Mar. Geol., 226, 127-144, doi:10.1016/ j.margeo.2005.09.013. 
Griffies, S., and Coauthors, 2011: The GFDL CM3 coupled climate model: Characteristics of the ocean and sea ice simulations. J. Climate, 24, 3520-3544, doi:10.1175/2011JCLI3964.1.

Grise, K. M., and L. M. Polvani, 2014: Southern Hemisphere cloud-dynamics biases in CMIP5 models and their implications for climate projections. J. Climate, 27, 6074-6092, doi:10.1175/JCLI-D-14-00113.1.

Henley, B. J., J. Gergis, D. J. Karoly, S. Power, J. Kennedy, and C. K. Folland, 2015: A tripole index for the interdecadal Pacific oscillation. Climate Dyn., 45, 3077-3090, doi:10.1007/ s00382-015-2525-1.

_ , and Coauthors, 2017: Spatial and temporal agreement in climate model simulations of the interdecadal Pacific oscillation. Environ. Res. Lett., 12, 044011, doi:10.1088/1748-9326/aa5cc8.

Hill, K. L., S. R. Rintoul, R. Coleman, and K. R. Ridgway, 2008: Wind forced low frequency variability of the East Australian Current. Geophys. Res. Lett., 35, L08602, doi:10.1029/ 2007GL032912.

- — - K. R. Ridgway, and P. R. Oke, 2011: Decadal changes in the South Pacific western boundary current system revealed in observations and ocean state estimates. J. Geophys. Res., 116, C01009, doi:10.1029/2009JC005926.

Hirabara, M., H. Ishizaki, and I. Ishikawa, 2007: Effects of the westerly wind stress over the Southern Ocean on the meridional overturning. J. Phys. Oceanogr., 37, 2114-2132, doi:10.1175/ JPO3112.1.

Holbrook, N. J., I. D. Goodwin, S. McGregor, E. Molina, and S. B. Power, 2011: ENSO to multi-decadal time scale changes in East Australian Current transports and Fort Denison sea level: Oceanic Rossby waves as the connecting mechanism. Deep-Sea Res. II, 58, 547-558, doi:10.1016/j.dsr2.2010.06.007.

IPCC, 2013: Climate Change 2013: The Physical Science Basis. Cambridge University Press, $1535 \mathrm{pp}$.

Kirtman, B., and Coauthors, 2013: Near-term climate change: Projections and predictability. Climate Change 2013: The Physical Science Basis, T. F. Stocker et al., Eds., Cambridge University Press, 953-1028.

Lukas, R., 2001: Freshening of the upper thermocline in the North Pacific subtropical gyre associated with decadal changes of rainfall. Geophys. Res. Lett., 28, 3485-3488, doi:10.1029/ 2001 GL013116.

Monselesan, D. P., T. J. O'Kane, J. S. Risbey, and J. Church, 2015: Internal climate memory in observations and models. Geophys. Res. Lett., 42, 1232-1242, doi:10.1002/2014GL062765.

O'Kane, T. J., R. J. Matear, M. A. Chamberlain, J. S. Risbey, B. M. Sloyan, and I. Horenko, 2013: Decadal variability in an OGCM Southern Ocean: Intrinsic modes, forced modes and metastable states. Ocean Modell., 69, 1-21, doi:10.1016/ j.ocemod.2013.04.009.

,,--- E. C. J. Oliver, and N. J. Holbrook, 2014: Storm tracks in the Southern Hemisphere subtropical oceans. J. Geophys. Res. Oceans, 119, 6078-6100, doi:10.1002/ 2014JC009990.

_ - D. P. Monselesan, and C. Maes, 2016: On the stability and spatiotemporal variance distribution of salinity in the upper ocean. J. Geophys. Res. Oceans, 121, 4128-4148, doi:10.1002/ 2015JC011523.

Oke, P. R., and M. J. England, 2004: Oceanic response to changes in the latitude of the Southern Hemisphere subpolar westerly winds.
J. Climate, 17, 1040-1054, doi:10.1175/1520-0442(2004)017<1040: ORTCIT $>2.0 . \mathrm{CO} ; 2$.

Power, S. B., and R. Colman, 2006: Multi-year predictability in a coupled general circulation model. Climate Dyn., 26, 247-272, doi:10.1007/s00382-005-0055-y.

_ - and J. Callaghan, 2016: Variability in severe coastal flooding, associated storms, and death tolls in southeastern Australia since the mid-nineteenth century. J. Appl. Meteor. Climatol., 55, 1139-1149, doi:10.1175/JAMC-D-15-0146.1.

, T. Casey, C. Folland, A. Colman, and V. Mehta, 1999: Interdecadal modulation of the impact of ENSO on Australia. Climate Dyn., 15, 319-324, doi:10.1007/s003820050284.

_ B. Sadler, and N. Nicholls, 2005: The influence of climate science on water management in Western Australia: Lessons for climate scientists. Bull. Amer. Meteor. Soc., 86, 839-844, doi:10.1175/BAMS-86-6-839.

and Coauthors, 2017: Towards the prediction of multi-year to decadal climate variability in the Southern Hemisphere. CLIVAR Exchanges, submitted.

Pyper, B. J., and R. M. Peterman, 1998: Comparison of methods to account for autocorrelation in correlation analyses of fish data. Can. J. Fish. Aquat. Sci., 55, 2127-2140, doi:10.1139/f98-104.

Rahmstorf, S., 1992: Modelling ocean temperatures and mixedlayer depths in the Tasman Sea off the South Island, New Zealand. N. Z. J. Mar. Freshwater Res., 26, 37-51, doi:10.1080/ 00288330.1992 .9516498$.

Rhein, M., and Coauthors, 2013: Observations: Ocean. Climate Change 2013: The Physical Science Basis, T. F. Stocker et al., Eds., Cambridge University Press, 255-315.

Schmitt, R. W., 2008: Salinity and the global water cycle. Oceanography, 21, 12-19, doi:10.5670/oceanog.2008.63.

Sen Gupta, A., N. C. Jourdain, J. N. Brown, and D. Monselesan, 2013: Climate drift in the CMIP5 models. J. Climate, 26, 85978615, doi:10.1175/JCLI-D-12-00521.1.

Sloyan, B. M., and T. J. O'Kane, 2015: Drivers of decadal variability in the Tasman Sea. J. Geophys. Res. Oceans, 120, 3193 3210, doi:10.1002/2014JC010550.

Sun, D., and Coauthors, 2006: Radiative and dynamical feedbacks over the equatorial cold tongue: Results from nine atmospheric GCMs. J. Climate, 19, 4059-4074, doi:10.1175/ JCLI3835.1.

Taylor, K. E., R. J. Stouffer, and G. A. Meehl, 2009: A summary of the CMIP5 experiment design. $33 \mathrm{pp}$. [Available online at http:// cmip-pcmdi.llnl.gov/cmip5/docs/Taylor_CMIP5_design.pdf.]

,-- and -2012 : An overview of CMIP5 and the experiment design. Bull. Amer. Meteor. Soc., 93, 485-498, doi:10.1175/BAMS-D-11-00094.1.

Tilburg, C. E., H. E. Hurlburt, J. J. O'Brien, and J. F. Shriver, 2001: The dynamics of the East Australian Current system: The Tasman Front, the East Auckland Current, and the East Cape Current. J. Phys. Oceanogr., 31, 2917-2943, doi:10.1175/ 1520-0485(2001)031<2917:TDOTEA > 2.0.CO;2.

— B. Subrahmanyam, and J. J. O'Brien, 2002: Ocean color variability in the Tasman Sea. Geophys. Res. Lett., 29, 1487, doi:10.1029/2001GL014071.

Yukimoto, S., and Coauthors, 2012: A new global climate model of the Meteorological Research Institute: MRI-CGCM3-Model description and basic performance. J. Meteor. Soc. Japan, 90, 23-64, doi:10.2151/jmsj.2012-A02. 